\title{
Preparation and Evaluation of Crosslinked Polyelectrolyte Complex Membranes
}

\author{
Soon Hong LEE \\ Department of Environmental Engineering, \\ Anyang University, Anyang, Kyunggi 430-714, Korea
}

(Received August 2, 1999; Accepted May 2, 2000)

\begin{abstract}
This article discusses a new method to make the crosslinked polyelectrolyte complex (PEC) membranes that has suitable mechanical strength, good solute permeability, hydrophilicity and biocompatibility in dialysis applications. PECs were obtained by mixing two aqueous solutions of water-soluble gelatin and carboxymethyl cellulose (CMC). PEC membranes were prepared under various conditions to determine a suitable mixing ratio of gelatin to CMC, concentration of crosslinking agent and film fablicating conditions, and their properties and permeability of solutes were estimated. Effects of the relative amounts of bound water and free water in the membrane on the solute permeation and mechanical properties were studied. This new PEC membrane not only offers higher solute permeability than the commercial Cuprophane membrane but also shows suitable mechanical strength, non-toxicity and non-pyrogen for dialysis application.
\end{abstract}

KEY WORDS Carboxymethyl Cellulose/Gelatin/Polyelectrolyte Complex/Crosslinking Agent/

Membrane / Solute Permeability / Biocompatibility /

Many polymers widely used for commercially available membranes and biomaterials are hydrophilic polymers, water-swellable polyelectrolyte complexes (PEC) and graft copolymers, such as hydroxylated polypropylene, ${ }^{1}$ sulfonated poly(vinyl alcohol) (PVA), ${ }^{2}$ acrylic acidgrafted methyl cellulose, ${ }^{3}$ sulfonated polyacrylonitrile, ${ }^{4}$ and various polyelectrolyte complexes. ${ }^{5-9}$ Polyelectrolyte complexes with high water content can easily be made by crosslinking already-formed polymers, or by simultaneously polymerizing and crosslinking various monomers.

Crosslinked PEC membranes provide good mechanical strength in the wet state and good permeability of water, small and midsize solutes depending on fabrication and crosslinking process conditions. The membranes have high water content and suitable water structure (bound and free water composition). The high water content and water structure influence the diffusion coefficient of the permeating soutes. It is generally accepted that polar groups such as $-\mathrm{COOH},-\mathrm{NH}_{2}$, and $-\mathrm{CHO}$ form hydrogen bonds with water but combine with themselves. This effect weakens the coherence of water clusters and causes efficient diffusion of solutes. ${ }^{10-13}$ The structure of water in membranes is also very important when diffusion takes place through water-swollen membranes. ${ }^{14}$ Solute diffusion does not take place in the bound water region that has strong hydrogen bonds, but in the free water region.

This work reports is the possibility of making novel hydrophilic membranes. ${ }^{1,2}$ Since commonly used cellulosic dialysis membranes exhibit low permeability and poor biocompatibility, this article focuses on the development of a modified cellulose membrane with improved permeability, mechanical strength in wet state and biocompatibility. Gelatin and CMC were blended to form a PEC membranes followed by crosslinking, and the performance of the membrane was studied.

\section{EXPERIMENTAL}

\section{Materials}

CMC (carboxylic acid content: $0.7 \mathrm{meq}^{-1}$ ) was purchased from Kisida Co. and gelatin ( $\mathrm{pH} 5.5-6.0,1 \mathrm{wt} \%$ solution) was obtained from Kyunggi Gelatin Co. Glutaraldehyde (Kokusan Chemical Works) as a crosslinking agent was used as received. Urea and sucrose were obtained from Wako Pure Chemicals. Poly(ethylene glycol) (PEG, $3400 \mathrm{~g} \mathrm{~mol}^{-1}$ ) and vitamin $\mathrm{B}_{12}$ were purchased from Polyscience and Rhone-Poulenc, respectively.

\section{Formation of (Gelatin/CMC) PEC}

Gelatin (aqueous solution of $0.5 \mathrm{wt} \%$ ) was mixed with $\mathrm{CMC}$ (aqueous solution of $0.5 \mathrm{wt} \%$ ) at $50^{\circ} \mathrm{C}$ with various weights and $\mathrm{pH}$ in the presence of acid. Ultraviolet spectrophotometer (Perkin Elmer, Model 559) was used to measure the maximum turbidity point against mixing ratio ( $R$, weight of gelatin / weight of gelatine and CMC) for gelatin / CMC system.

\section{Preparation of Crosslinked (Gelatin/CMC) PEC Mem- branes}

In the preparation of crosslinked PEC membrane, the homogeneous PEC solution (gelatin : $\mathrm{CMC}=2.3: 1$ ) was cast on the glass plate kept at $50^{\circ} \mathrm{C}$ and spread with a casting bar equipped with a spacer. The solvent was allowed to preevaporate at $10^{\circ} \mathrm{C}$ until the gel film was obtained and completely dried in a freeze dryer. The resulting film was immersed in a bath of acetic acid ( $\mathrm{pH} 3)$ to form a PEC membrane. The PEC membrane was washed with distilled water and completely dried at $40^{\circ} \mathrm{C}$ for 1 day under vacuum. The polyelectrolyte complex(PEC) membrane was crosslinked for $12 \mathrm{~h}$ in aqueous solution of glutaraldehyde $\left(1,4\right.$, and $7 \mathrm{~mol} \mathrm{~L}^{-1}$ for sample A-1, A-2, and A-3, respectively) to improve mechanical strength in the wet state. Change in the proper- 
ties of cellulosic substrates resulting from treatments with crosslinking agent under various conditions has been studied. It is generally accepted that crosslinking agent condenses with CMC with loss of water to form intermolecular crosslinks between macromolecular chains and provides improved wet strength. The resulting crosslinked PEC membranes were washed with distilled water and dried before evaluating performance.

\section{Measurements}

FT-IR (Nicolet, Model 5DX) was used to determine the composition of PEC. The morphology of the completely dehydrated PEC membrane was photographed using a scanning electron microscope (SEM, Hitachi, S-510). To measure water content, samples were immersed in distilled water for 7 days. Water content at equilibrium was determined according to the following equation, $Q_{\mathrm{u}}(\%)=$ $\left[\left(W_{\mathrm{s}}-W_{\mathrm{d}}\right) / W_{\mathrm{s}}\right] \times 100$, where $W_{\mathrm{s}}$ and $W_{\mathrm{d}}$ denote weight of wet and dry samples, respectively. To evaluate the water structure in the membrane, a DuPont 910 thermal analyzer and cell base were used for all melting measurements. A membrane sample $(6-15 \mathrm{mg})$ equilibrated at $37^{\circ} \mathrm{C}$ was sealed in an aluminum pan and cooled with liquid nitrogen to $-70^{\circ} \mathrm{C}$ in DSC. The cell was slowly heated in a stream of nitrogen gas at a program rate of $5^{\circ} \mathrm{C}$ min $^{-1}$ up to $20^{\circ} \mathrm{C}$. Tensile strength and elongation under the dry and wet state were estimated according to ASTM D-638 by an Instron Model 4201 with a crosshead speed of $10 \mathrm{~mm} \mathrm{~min}^{-1}$ and $5 \mathrm{Kg}_{\mathrm{f}}$ load cell was used.

\section{Permeation Experiment}

The permeation cell in this study had two compartments of equal volume $(100 \mathrm{~mL})$ as shown in Figure 1. Temperature of the compartment was maintained at $37^{\circ} \mathrm{C}$ with a constant stirring at $300 \mathrm{rpm}$ to eleminate any concentration polarization. Concentrations of urea, sucrose, vitamin $\mathrm{B}_{12}$, and PEG 3400 were 200, 200, 50, and $100 \mathrm{mg} \mathrm{L}^{-1}$, respectively. Concentrations in the feed and permeating compartments were detected using ultraviolet spectrophotometer and differential refractometer (Waters, Model R 403). Particularly for the vitamine $\mathrm{B}_{12}$ solution, the light was blocked during permeation to obtain precise absorption curves measured at $550 \mathrm{~nm}$.

The solute permeability coefficient $P$ was calculated from the following equation obtained from mass balance equation, i.e.,

$$
P=\frac{-d}{A\left(1 / V_{1}+1 / V_{2}\right) t} \times \ln \left[\left(1+\frac{V_{1}}{V_{2}}\right) \frac{C_{\mathrm{t}}}{C_{0}}-\frac{V_{1}}{V_{2}}\right]
$$

where $V_{1}, V_{2}, A, d, C_{0}$, and $C_{\mathrm{t}}$ are the volumes of the concentrated and dilute compartment, membrane area $(9.62$ $\mathrm{cm}^{2}$ ), thickness, and concentrations of the concentrated compartment at times 0 and $t$, respectively.

\section{Chemical Toxicity and Pyrogen Test}

Chemical toxicity and pyrogen test for biomedical application were performed with the help of Green-Cross Medical Co. according to the USP rabbit test. ${ }^{15}$

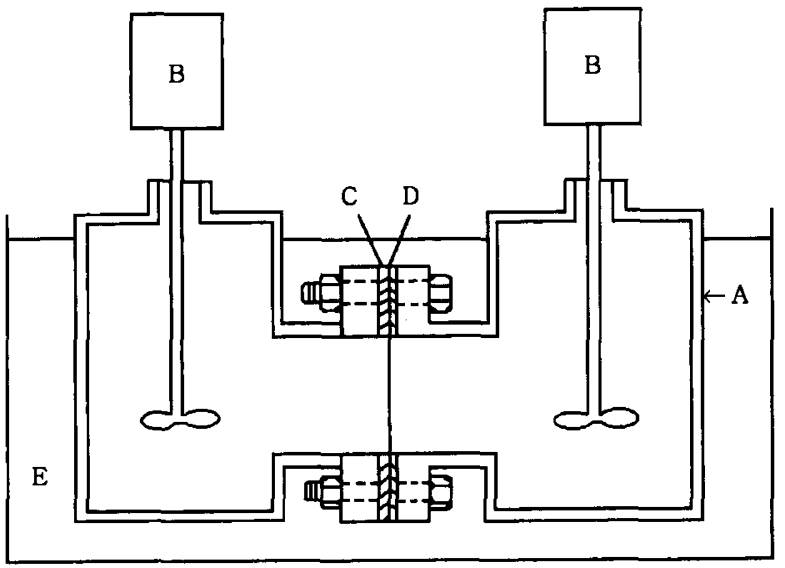

Figure 1. Solute permeability measurement apparatus: A, glass cell; B, mechanical stirrer; C, silicon rubber ring; D, PEC membrane; E, water bath.

\section{RESULTS AND DISCUSSION}

\section{Formation of (Gelatin-CMC) PEC}

In PEC systems composed of synthetic polymers, actual complexation reactions cannot be accurately predicted. Very simple theories based on colloidal chemistry were proposed by Oosawa ${ }^{16}$ and Nakajima, ${ }^{17}$ who consider very simple and specific models and assume a homogeneous distribution of molar mass with no contribution from interaction forces other than electrostatic interactions.

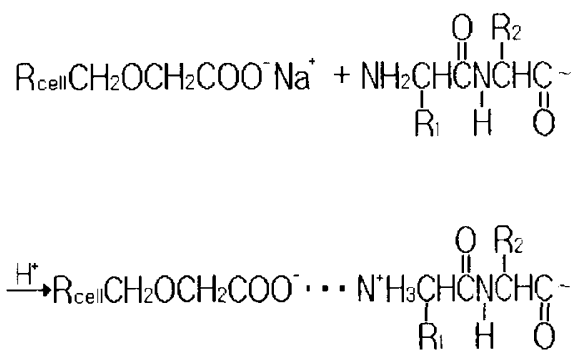

\section{(Gelatin-CMC) PEC}

Optimum conditions for the PEC formation were confirmed by complex phase separation curves influenced by effects of mixing ratio of gelatin and $\mathrm{CMC}$ at various pH. Figure 2 shows that PEC was formed well at all mixing ratio of gelatin and $\mathrm{CMC}$ in the range of $\mathrm{pH} 2.4-5.2$. As the amount of gelatin increased, PEC was formed well up to $\mathrm{pH} 5$. From the turbidity test for various mixtures of gelatin and $\mathrm{CMC}$ at $\mathrm{pH} 2$ and 3 , minimum transmittance at $575 \mathrm{~nm}$ was 70 and $72 \%$ in the mixing ratio of about 0.63 and 0.70 , respectively as shown in Figure 3 . The ideal mixing ratio of gelatin to CMC for the maximum complex phase separation was approximately $1.7: 1$ at $\mathrm{pH} 2$ and $2.3: 1$ at $\mathrm{pH} 3$.

Non-crosslinked PEC film was identified by FT-IR and corresponding features are shown in Figure 4. In the spectrum of PEC the amide I band and amide II band of 


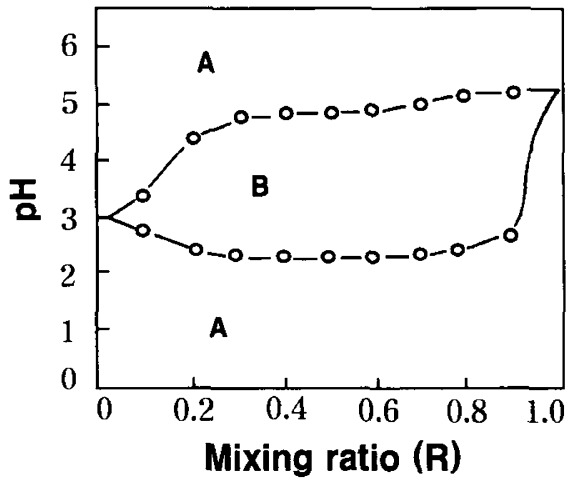

Figure 2. Complex phase separation influenced by $\mathrm{pH}$ and mixing ratio of gelatin and $\mathrm{CMC}$ : $\mathrm{A}$, homogeneous phase; $\mathrm{B}$, separation phase.

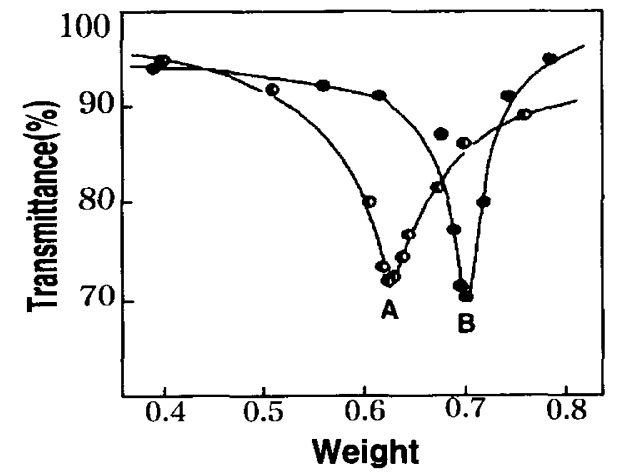

Figure 3. Turbidity curves plotted against $\mathrm{pH}$ for $\mathrm{PEC}$ formation of (gelatin and $\mathrm{CMC}$ ) at $575 \mathrm{~nm}: \mathrm{A}, \mathrm{pH} 2 ; \mathrm{B}, \mathrm{pH} 3$.

the gelatin appear at $1655 \mathrm{~cm}^{-1}, 1535 \mathrm{~cm}^{-1}$, respectively, at $1447 \mathrm{~cm}^{-1}$ as for the ionized carboxylate band of CMC. In addition to FT-IR results, water insolubility of the non-crosslinked PEC film is indirect evidence for PEC formation.

Properties and Morphology of Crosslinked (GelatinCMC) PEC Membrane

The concentration of crosslinker more than $7 \mathrm{~mol} \mathrm{~L}^{-1}$ did not greatly affect the improvement of physical properties, morphology and permeability characteristics. Therefore, concentration of the crosslinking agent for prepering sample were varied and the optimal value was selected for the membrane.

In the formation of (gelatin-CMC) PEC, condensation of charge by electric interaction may give the multiplx structure first proposed by Eisenberg, ${ }^{18}$ and results in the formation of strong ionic crosslinking. Therefore, remaining reactive species $(-\mathrm{OH})$ of $\mathrm{CMC}$ may react with the crosslinking agent in the preparation of crosslinked (gelatin-CMC) PEC membrane.

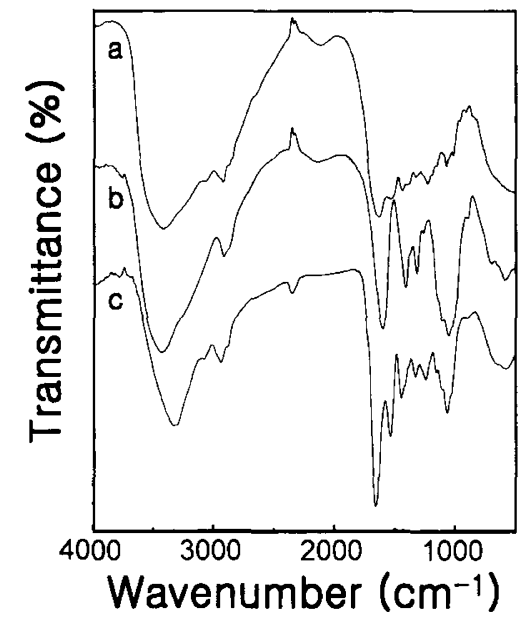

Figure 4. Infrared spectra of gelatin, CMC and polyelectrolyte complex: a, gelatin; b, CMC; c, polyelectrolyte complex.

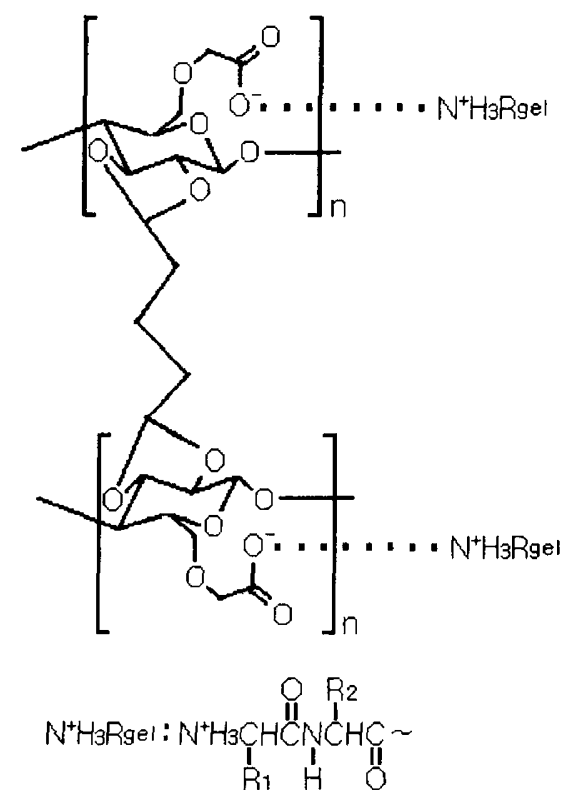

Crosslinked (Gelatin-CMC)PEC

Table I lists the characteristics of all the resulting membranes. The concentration of crosslinking agent influenced the physical properties of the membrane. Water content of samples decreased with growing crosslinking density and was higher than that of commercially available Cuprophane membrane (about 50\%). Tensile strength of samples in dry state is regarded as excellent. However, in wet state, all samples have comparable tensile strength $\left(0.28-0.35 \mathrm{~kg} \mathrm{~mm}^{-2}\right)$ to that of commercial Cuprophane membrane $\left(0.30 \mathrm{~kg} \mathrm{~mm}^{-2}\right) .{ }^{19}$ Tensile strength changed depending on the concentration of crosslinking agent and morphology of the membrane. This may be explained by cross-sectional views of the A1, A-2, and A-3 membranes in Figure 5, where the membrane becomes more dense as the concentration of crosslinking agent in a crosslinking process increases. As the crosslinking density increased, elongation in the wet state decreased greatly at $127-31 \%$. All samples 
Table I. Summary of preparation and physical properties of crosslinked PEC membranes

Preparation conditions

Concentration

of

\begin{tabular}{|c|c|c|c|}
\hline \multirow[t]{3}{*}{ Sample } & \multirow{2}{*}{\multicolumn{2}{|c|}{ Mixing ratio }} & \multirow{3}{*}{$\begin{array}{c}\begin{array}{c}\text { of } \\
\text { crosslinker }\end{array} \\
\text { mol L }^{-1}\end{array}$} \\
\hline & & & \\
\hline & Gelatin ${ }^{a}$ & $\mathrm{CMC}^{\mathrm{a}}$ & \\
\hline A-1 & 2.3 & 1 & 1 \\
\hline A-2 & 2.3 & 1 & 4 \\
\hline A-3 & 2.3 & 1 & 7 \\
\hline
\end{tabular}

${ }^{a}$ Aqueous solution $(0.5 \mathrm{wt} \%)$.

Table II. Permeability coefficients for aqueous solutions of various solutes and calculated bound and free water in crosslinked PEC membranes

\begin{tabular}{|c|c|c|c|c|c|c|c|}
\hline \multirow{3}{*}{ Sample } & \multirow{2}{*}{\multicolumn{4}{|c|}{$\begin{array}{l}\text { Permeability } \times 10^{7} \\
\mathrm{~cm}^{3} \mathrm{~cm} \mathrm{~cm}^{-2} \mathrm{~s}^{-1}\end{array}$}} & \multirow{3}{*}{$\begin{array}{c}W_{\mathrm{t}}, \\
\frac{\text { Water content }}{\%}\end{array}$} & \multirow{3}{*}{$\begin{array}{c}W_{\mathrm{b}} \text {, } \\
\text { Fraction of } \\
\text { bound water }\end{array}$} & \multirow{3}{*}{$\begin{array}{c}\qquad W_{\mathrm{f}}, \\
\text { Fraction of } \\
\text { free water }\end{array}$} \\
\hline & & & & & & & \\
\hline & Urea & Sucrose & Vitamin $\mathrm{B}_{12}$ & PEG 3400 & & & \\
\hline A-1 & 12.7 & 2.5 & 0.63 & 0.27 & 69.0 & 0.34 & 0.66 \\
\hline A-2 & 10.3 & 2.0 & 0.58 & 0.21 & 64.7 & 0.39 & 0.61 \\
\hline A-3 & 8.7 & 1.8 & 0.45 & 0.13 & 51.8 & 0.47 & 0.53 \\
\hline Cuprophane $^{\text {a }}$ & 4.8 & 2.0 & 0.57 & - & 50.0 & - & - \\
\hline
\end{tabular}

${ }^{a}$ Data taken from ref 20.
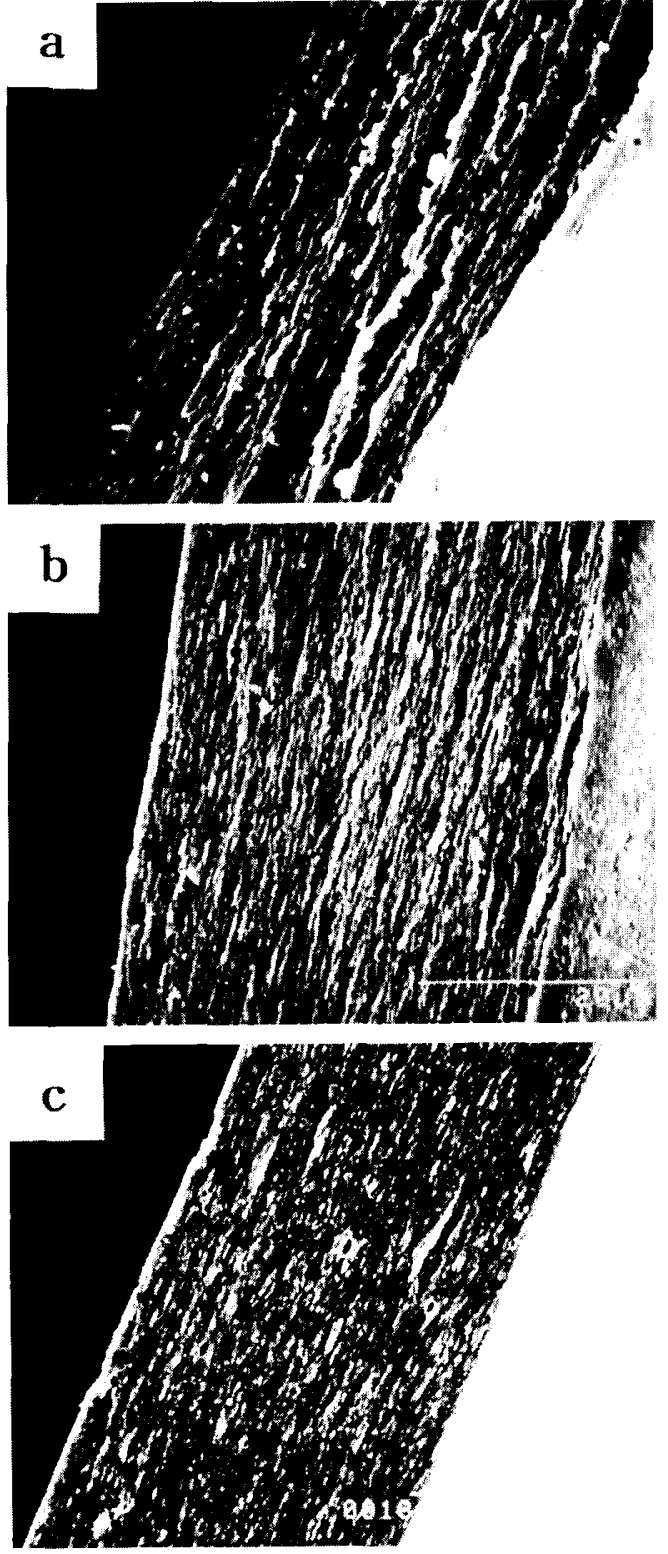

Figure 5. Scanning electron micrographs of crosslinked PEC membranes ( $\times 1750)$ : a, A-1; b, A-2; c, A-3. were suitable for dialysis.

\section{Solute Permeabilities of (Gelatin-CMC) Membranes}

Table II shows the permeability of A-1, A-2, and A-3 membranes for four solutes at $37^{\circ} \mathrm{C}$. The concentrations of urea, sucrose, vitamin $\mathrm{B}_{12}$, and PEG 3400 were 200 , 200,50 , and $100 \mathrm{mg} \mathrm{L}^{-1}$ in water, respectively. Only a single membrane was used for each evaluation. Permeability for solutes changes according to affinity between solute and hydrophilic group in the membane material, water structure (weight fraction of free and bound water) in the membane, porosity and morpholoy of membrane. Crosslinked (gelatine-CMC) PEC membranes have higher water content $(69.0-51.8 \%)$ than $(50.0 \%)$ Cuprophane, so that solutes pass through the membrane easily. A large molecule has difficulty in diffusing through the membrane compared with a small molecule. Molecular sizes of urea and sucrose are $8.1 \AA^{2}, 27.7 \AA^{2}$, respectively. Therefore, high permeability of urea was also due to comparably small molecular size and low molecular weight. All the membranes showed good permeability of solutes, and urea permeability 2-3-fold higher than that of Cuprophane. ${ }^{20}$ Solute permeability decreases as molecular weight of solutes increases, and all the membranes show similar molecular weight dependency. Molecular weights of urea, creatinine, vitamin $B_{12}$, and PEG were $60,113,1355$, and $3500 \mathrm{~g} \mathrm{~mol}^{-1}$, respectively. It is generally accepted that a large molecule has difficulty in diffusing through the membrane compared with a small molecule. Therefore, compard to small molecular weight of solute, large molecular weight of solute has less permeability through the membrane. With increasing molecular weight of solute, solute permeability decreases almost linearly. Solute permeability also increases with water content in the membrane. This is mainly attributed to the water structure inside the membrane. Water soluble solutes diffuse through the membrane via water pockets of clustered water. ${ }^{21,22}$ If water content of membrane increase to some extent, water pockets expand largely and solutes diffuse through the membrane easily. 
S. H. LEE

Table III. Chemical toxicity test results of extracts obtained from crosslinked (gelatin-CMC) PEC membranes

\begin{tabular}{|c|c|c|c|c|c|c|}
\hline \multirow{2}{*}{ Sample } & \multirow{2}{*}{$\frac{\mathrm{pH}}{\text { deviation }^{\mathrm{a}}}$} & \multirow{2}{*}{$\begin{array}{l}\text { Heavy } \\
\text { metals } \\
\mathrm{mg} \mathrm{L}^{-1}\end{array}$} & \multicolumn{2}{|c|}{ UV absorbance } & \multirow{2}{*}{$\begin{array}{c}\begin{array}{c}\text { Total } \\
\text { solids }\end{array} \\
\mathrm{mg} \mathrm{mL}^{-1}\end{array}$} & \multirow{2}{*}{$\begin{array}{c}\begin{array}{c}\text { Oxidizable } \\
\text { substances }\end{array} \\
\mathrm{mL}\end{array}$} \\
\hline & & & $200-241 \mathrm{~nm}$ & $241-350 \mathrm{~nm}$ & & \\
\hline $\begin{array}{l}\text { Standard } \\
\text { Extracts }\end{array}$ & $\begin{array}{l}1.5< \\
0.183\end{array}$ & $\begin{array}{l}<20 \\
\text { Pass }\end{array}$ & $\begin{array}{l}<0.08 \\
0.021\end{array}$ & $\begin{array}{l}<0.05 \\
0.001\end{array}$ & $\begin{array}{l}<10 \\
0.18\end{array}$ & $\begin{array}{c}<1.0 \\
0.2\end{array}$ \\
\hline
\end{tabular}

${ }^{\mathrm{a}}$ Standard $\mathrm{pH}: 7$ (distilled water). ${ }^{\mathrm{b}}$ Based on $\mathrm{KMnO}_{4}$ consumption.

Table IV. Pyrogen test results of extracts obtained from crosslinked (gelatin-CMC) PEC membranes

\begin{tabular}{|c|c|c|c|c|c|c|c|c|}
\hline \multirow{2}{*}{$\begin{array}{c}\text { Rabbit } \\
\text { no. }\end{array}$} & \multirow{2}{*}{$\begin{array}{c}\begin{array}{c}\text { Body } \\
\text { weight }\end{array} \\
\mathrm{kg}\end{array}$} & \multirow{2}{*}{$\frac{\text { Injection }}{\mathrm{mL}}$} & \multicolumn{4}{|c|}{ Body temperature $/{ }^{\circ} \mathrm{C}$} & \multirow{2}{*}{$\begin{array}{c}\begin{array}{c}\text { Raised } \\
\text { temp }\end{array} \\
{ }^{\circ} \mathrm{C}\end{array}$} & \multirow{2}{*}{$\begin{array}{c}\text { Total } \\
\text { raised } \\
\text { temp }{ }^{b} \\
{ }^{\circ} \mathrm{C}\end{array}$} \\
\hline & & & Primary & \multicolumn{3}{|c|}{ After injection } & & \\
\hline R 1 & 2.0 & 20 & 38.9 & 38.8 & 38.8 & 39.0 & 0.1 & \\
\hline $\mathrm{R} 2$ & 2.0 & 20 & 38.8 & 38.8 & 38.8 & 38.9 & 0.1 & \\
\hline R 3 & 2.0 & 20 & 38.7 & 38.8 & 38.9 & 39.2 & 0.5 & $(0.7)$ \\
\hline
\end{tabular}

${ }^{a}$ Standard $<1.0^{\circ} \mathrm{C} .{ }^{\mathrm{b}}$ Elapsed time after injection $(\mathrm{h})$.

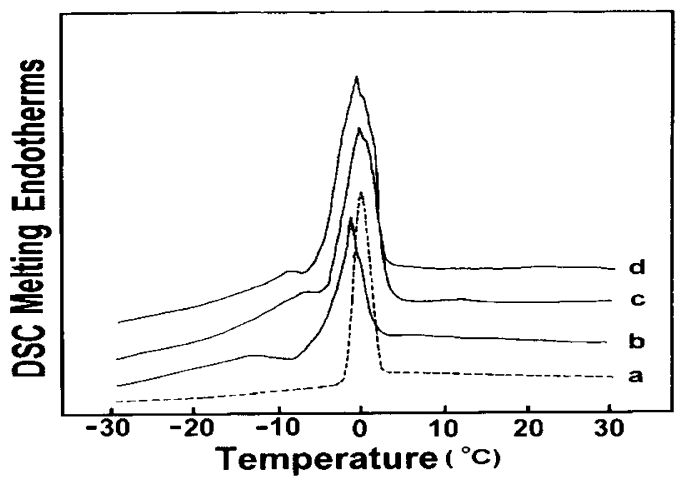

Figure 6. DSC melting endotherms of free water in PEC membranes and pure water: a, pure water; b, 51.8\%; c, 64.7\%; d, 69.0\%.

Figure 6 shows DSC heating curves of water-swollen (gelatin-CMC) PEC membranes and pure water. With increase in swelling ratio of membrane, an endothermic peak appearing at around $0^{\circ} \mathrm{C}$ due to the presence of free water grew and separated into two peaks, one close to $0^{\circ} \mathrm{C}$ and the other shifting toward $-4^{\circ} \mathrm{C}$. These endothermic peaks confirm two types of water in the membrane, ${ }^{22}$ i.e., free water and freezing bound water. The former has a melting temperature comparable with that of bulk water (curve a in Figure 6). The latter shows a lower temperature peak presumably by weak interaction between water and the polymer chain.

Freezing and nonfreezing water in the membranes are listed in Table II for different PEC membranes, calculated from enthalphies given by the areas of peaks appearing at -4 and $0^{\circ} \mathrm{C}$. Bound water in the membrane was approximately estimated as,

$$
W_{\mathrm{b}}=W_{\mathrm{t}}-\left(W_{\mathrm{f}}+W_{\mathrm{fb}}\right)=W_{\mathrm{t}}-Q_{\text {endo }} / Q_{\mathrm{f}}
$$

where $W_{\mathrm{b}}$ and $W_{\mathrm{t}}$ are weights of bound and total water in the membrane, respectively. $W_{\mathrm{f}}$ and $W_{\mathrm{fb}}$ are the weight fractions of free water and freezing bound water, respectively. The sum of $W_{\mathrm{f}}$ and $W_{\mathrm{fb}}$ is the ratio of $Q_{\text {endo }} / Q_{\mathrm{f}}$, where $Q_{\text {endo }}$ is the observed endothermic heat ( $\mathrm{cal} \mathrm{g}^{-1}$ ) originating from bound and freezing bound water from water-swollen membrane and $Q_{\mathrm{f}}$ is the heat fusion of ice $\left(79.8 \mathrm{cal} \mathrm{g}^{-1}\right)$. Sharp endothermic peaks at around $0^{\circ} \mathrm{C}$ are assigned to free water, and other peaks at lower temperatures to freezing bound water (intermediate water). But all endothermic peaks at lower temperatures are not as remarkable as those for the free water in the membranes. Freezing water in the membranes consists mostly of free water and a very small amount of freezing bound water. Therefore, freezing water in the membranes was regarded as free water in this study. Total water content increases as the membrane becomes less crosslinked and porous. Total water content is equal to sum up of bound water and free water. Therefore, water after calculation of free water from the total water content in the membrane is considered bound water. With increase of crosslinking of PEC, a denser membrane was obtained, and free water decreased. Remaining hydrophilic groups after PEC formation decrease with increase of crosslinking. Water that interacted with hydrophilic groups may be considered free water, and its bonding force is weak compared with that of bound water. The weight fraction of bound water in the resultant membrane thus increases.

Free water increases while the fraction of bound water becomes less as the membranes become crosslinked and porous. The more the increase in total water, the greater the permeability of solutes through the membrane. Free water and freezing bound water may easily form water clusters by hydrogen bonding with each other, but bonding force is obviously weaker than that between bound water. Bound water may be difficult to move because it strongly combines with polymer chains. Therefore, solutes find difficulty in diffusing through this region and may rather pass through the region of free water. Greater free water coupled with porosity in the membrane contributes to the permeation of solutes through the membrane.

\section{Chemical Toxicity and Pyrogen Test}

Table III and IV show chemical toxicity and pyrogen test results of extracts obtained from A-1, A-2, A-3 mem- 
branes, respectively. The chemical toxicity test on extracts of the membranes satisfied the standard requirements of toxicity level for the biomedical materials. In the pyrogen test for three-rabbit test, raised body temperature after injection of extracts was $0.1-0.5^{\circ} \mathrm{C}$ and total body temperature $\left(0.7^{\circ} \mathrm{C}\right)$ was less than maximum permitted limit $\left(1^{\circ} \mathrm{C}\right)$. Materials judged non-pyrogenic in the rabbit test are non-pyrogenic in man. The crosslinked (gelatine-CMC) PEC membranes reported here may be used for dialysis in consideration of physical properties, solute permeability, non-toxicity and nonpyrogen.

\section{CONCLUSION}

New crosslinked (gelatin-CMC) PEC membranes were developed, with good physical properties and dialysis performance as well as biocompatibility (non-toxicity and non-pyrogen). Tensile strength in the wet state of membrane ranged from 0.28 to $0.33 \mathrm{~kg} \mathrm{~mm}^{-2}$, while water content was $53.5-69.0 \%$. The A-1 membrane shows higher permeability of solutes and comparable mechanical properties than the commercial Cuprophane membrane had. The permeability of solutes correlated well with water content or free water in the membrane. With casting-drying-crosslinking, procedures to prepare water swellable membranes with controllable physical properties, morphology and solute permeability were demonstrated.

\section{REFERENCES}

1. T. C. Chung and S. H. Lee, J. Appl. Polym. Sci., 64, 567 (1997).
2. H. J. Chun, J. J. Kim, S. H. Lee, U. Y. Kim, and K. Y. Kim, Polym. J., 22, 477 (1990).

3. V. Shantora and R. Y. M. Huang, J. Appl. Polym. Sci., 26, 3223 (1981).

4. N. Man, B. Teslain, J. Paris, G. Werner, A. Sausse, and J. L. Funck-Brentano, Trand. Amer. Soc. Artif. Int. Organs, 19, 320 (1973).

5. A. S. Michaels and R. G. Miekka, J. Phys. Chem., 65, 1765 (1961).

6. L. L. Markley, H. J. Bixler, and R. A. Cross, J. Biomed. Mater. Res., 2, 145 (1968).

7. M. F. Refoja, J. Appl. Polym. Sci., 11, 1991 (1967).

8. H. Fukuda and Y. Kikuchi, J. Biomed. Mater. Res., 12, 531 (1978).

9. K. Kataoka, M. Maeda, T. Nichimura, Y. Nitadori, and T. Tsuruta, J. Biomed. Mater. Res., 14, 817 (1980).

10. H. Frank, Proc. R. Soc. London, Ser. A, 247, 481 (1958).

11. D. Ferry, Chem. Rev., 18, 373 (1958).

12. J. Morgan and B. Warren, J. Chem. Phys., 6, 666 (1938).

13. D. B. Pedley and B. J. Tighe, Br. Polym., J., 11, 130 (1979).

14. N. A. Peppas and H. J. Moynihan, J. Appl. Polym. Sci., 30, 2589 (1985).

15. United States Pharmacopia, XIX, Mack Publishing Co., Easton, Pennsylvania, 613 (1975).

16. F. Oosawa, Biopolymers, 6, 1633 (1968).

17. H. Okihana and A. Nakajima, Bull. Inst. Chem. Res., Kyoto Univ., 54, 63 (1976).

18. A. Eisenberg, 'Ion containing polymers', in "Polymer Physies," Vol. 2, Academic Press, New York, N.Y., 1977.

19. S. Yamashita, K. Takakura, Y. Imai, and E. Masuhara, Kobunshi Ronbunshu, 35, 283 (1978).

20. N. Nishioka, S. Yoshimi, T. Iwaguchi, and K. Kosai, Polym. J., 16, 877 (1984).

21. T. A. Jadwin, A. S. Hoffman, and W. R. Vieth, J. Appl. Polym. Sci., 14, 1339 (1970).

22. S. C. Yoon and M. S. Jhon, J. Appl. Polym. Sci., 27, 4661 (1982). 